\title{
RNA interference-mediated silencing of BACE and APP attenuates the isoflurane-induced caspase activation
}

\author{
Yuanlin Dong ${ }^{1}$, Zhipeng $\mathrm{Xu}^{1}$, Yiying Zhang ${ }^{1}$, Sayre McAuliffe ${ }^{1}$, Hui Wang ${ }^{1,2}$, Xia Shen $^{1,3}$, Yun Yue $^{2}$ and \\ Zhongcong Xie ${ }^{1 *}$
}

\begin{abstract}
Background: $\beta$-Amyloid protein (A $\beta$ ) has been shown to potentiate the caspase-3 activation induced by the commonly used inhalation anesthetic isoflurane. However, it is unknown whether reduction in $A \beta$ levels can attenuate the isoflurane-induced caspase-3 activation. We therefore set out to determine the effects of RNA interference-mediated silencing of amyloid precursor protein (APP) and $\beta$-site APP-cleaving enzyme (BACE) on the levels of $A \beta$ and the isoflurane-induced caspase-3 activation.

Methods: H4 human neuroglioma cells stably transfected to express full-length human APP (H4-APP cells) were treated with small interference RNAs (siRNAs) targeted at silencing BACE and APP for 48 hours. The cells were then treated with $2 \%$ isoflurane for six hours. The levels of BACE, APP, and caspase-3 were determined using Western blot analysis. Sandwich Enzyme-linked immunosorbent assay (ELISA) was used to determine the extracellular $A \beta$ levels in the conditioned cell culture media.

Results: Here we show for the first time that treatment with BACE and APP siRNAs can decrease levels of BACE, full-length APP, and APP c-terminal fragments. Moreover, the treatment attenuates the A $\beta$ levels and the isoflurane-induced caspase- 3 activation. These results further suggest a potential role of $A \beta$ in the isofluraneinduced caspase- 3 activation such that the reduction in $A \beta$ levels attenuates the isoflurane-induced caspase-3 activation.
\end{abstract}

Conclusion: These findings will lead to more studies which aim at illustrating the underlying mechanism by which isoflurane and other anesthetics may affect Alzheimer's disease neuropathogenesis.

\section{Background}

Alzheimer's disease (AD), one of the most common forms of dementia, affects 4.5 million Americans and costs more than $\$ 100$ billion a year on direct care alone. Its impact will only increase in the coming decades. AD is an insidious and progressive neurodegenerative disorder and is characterized by global cognitive decline, robust accumulation of amyloid deposits, and neurofibrillary tangles in the brain [reviewed in [1]]. Genetic evidence, confirmed by neuropathological and biochemical findings, indicates that excessive production and/or

\footnotetext{
* Correspondence: zxie@partners.org

'Geriatric Anesthesia Research Unit, Department of Anesthesia, Critical Care and Pain Medicine, Massachusetts General Hospital and Harvard Medical School, Charlestown, MA 02129-2060; USA

Full list of author information is available at the end of the article
}

accumulation of $\beta$-amyloid protein (A $\beta$ ) play a fundamental role in the pathology of $\mathrm{AD}$ [reviewed by $[1,2]$ ]. $A \beta$ is produced from amyloid precursor protein (APP) through proteolytic processing by the aspartyl protease $\beta$-site APP-cleaving enzyme (BACE) and $\gamma$-secretase [reviewed in [3]].

Increasing evidence suggests a role for caspase activation and apoptosis in AD neuropathogenesis [[4-13], reviewed in $[14,15]]$. There has been debate in regards to the contribution of apoptosis to neuronal loss in $\mathrm{AD}$ because the apoptotic markers are rarely detected in the brain of AD patients [reviewed in [16,17]]. However, this could be due to the long duration of $\mathrm{AD}$ and very rapid clearance of apoptotic cells from organs. Recent studies employing antibodies that specifically recognize
C Biomed Central

다 2011 Dong et al; licensee BioMed Central Ltd. This is an Open Access article distributed under the terms of the Creative Commons Attribution License (http://creativecommons.org/licenses/by/2.0), which permits unrestricted use, distribution, and reproduction in any medium, provided the original work is properly cited. 
caspase-cleaved substrates have shown that caspase-3cleaved-actins, caspase-3-cleaved fragments, and caspase-cleaved-APPs are present in AD patients' brains [18-31]. Western blot analysis has also revealed increased caspase- 3 immunoreactivity in AD versus control brains [24,32,33]. In addition, activated caspase- 6 and caspase- 9 have been detected in AD brains $[25,26]$.

An estimated 200 million patients worldwide undergo anesthesia and surgery each year [34,35]. Both surgery and anesthesia have been suggested to play a role in the progress of $\mathrm{AD}$ neuropathogenesis [reviewed in [36,37]] and AD. Specifically, the age of onset of $\mathrm{AD}$ has been reported to be inversely related to cumulative exposure to anesthesia and surgery before the age of 50 years [38], even though anesthesia and/or surgery themselves may not increase the incidence of AD [39]. Another study showed that patients having coronary artery bypass graft surgery under general anesthesia may be at increased risk for AD as compared to those having percutaneous transluminal coronary angioplasty under local anesthesia [40]. A recent retrospective population-based study has found that general anesthesia is a risk factor of $\mathrm{AD}$ with an adjusted odds ratio of 3.22 [41]. Moreover, cognitive dysfunction or decline occurs after anesthesia and surgery [[42-52], reviewed in 53], which is associated with impairments in daily functioning [54], dependency on government economic assistance [52], and increased morbidity and mortality [[42,55], reviewed in [56]]. However, opposing findings also exist [57-59]. Therefore, more clinical studies, which will define the role of anesthesia and/or surgery in $\mathrm{AD}$ and in postoperative cognitive dysfunction or decline, are necessary [60].

Given the fact that adequately powered prospective human studies will take many years to conduct and analyze, it is equally important to perform animal and in vitro studies, which will complement ongoing human studies, e.g., by establishing a mechanistic hypothesis. Several studies have shown that the commonly used inhalation anesthetic isoflurane may induce caspase activation, apoptosis, $\mathrm{A} \beta$ oligomerization and accumulation, neuroinflammation, tau protein hyperphosphorylation, mitochondrial dysfunction, and impairment of learning and memory [[60-69], reviewed in [36,37]]. However, the underlying mechanisms of these effects remain largely to be determined. Our studies in cultured cells have shown that exogenerously administrated $A \beta$ into the cell culture media can potentiate the isofluraneinduced caspase activation and apoptosis, which may induce further rounds of apoptosis and $A \beta$ generation [70]. In the present studies, we set out to determine the effects of RNA interference (RNAi)-mediated silencing of BACE and APP on A $\beta$ levels and the isofluraneinduced caspase activaion in cultured cells to further elucidate the potential association of $\mathrm{A} \beta$ accumulation and the isoflurane-induced caspase- 3 activation.

\section{Methods \\ Cell lines}

We employed H4 human neuroglioma cells stably transfected to express full-length human APP (H4-APP cells) in the experiments. We used H4-APP cells for the easy measurement of $A \beta$ levels in the conditioned cell culture media as we did in the previous studies [65,70,71]. The cells were cultured in Dulbecco's modified Eagle's medium (high glucose) containing 9\% heat-inactivated fetal calf serum, 100 units $/ \mathrm{ml}$ penicillin, $100 \mathrm{~g} / \mathrm{ml}$ streptomycin, and $2 \mathrm{mM}$ L-glutamine and was supplemented with $20 \mathrm{~g} / \mathrm{ml} \mathrm{G} 418$.

\section{RNAi studies}

RNAi-mediated silencing of BACE and APP experiments were similar to those in our previous studies [72-76]. In order to avoid off-target effects of RNAi, we employed two sets of small interference RNAs (siRNAs) aimed at silencing of BACE ( $1^{\text {st }}$ set: 3'GCAAGGAGUACAACUAUGAUU; $2^{\text {nd }}$ set: 3'GGAGGGAGCAUGAUCAUUGUU) and APP ( $1^{\text {st }}$ set: $3^{\prime}$ GGUGGGCGGUGUUGUCAUA; $2^{\text {nd }}$ set: 3' GGUUCUGGGUUGACAAAUA). These siRNAs and control siRNA (3'UAGCGACUAAACACAUCAAUU) were obtained from Dharmacon (Lafayette, CO). siRNAs were transfected into cells using electroporation (AMAXA, Gaithersburg, MD) as described by Xie et al [75]. Briefly, we mixed 1 million cells, 100 ul AMAXA electroporation transfection solution and $10 \mathrm{ul} 20 \mathrm{uM}$ siRNA together, then we employed C-9 program in an AMAXA electroporation device for cell transfection. The transfected cells were then placed in one of the six-well plates containing $1.5 \mathrm{ml}$ cell culture media. The BACE, APP, or control siRNA-pretreated cells were then exposed to the isoflurane treatment 48 hours later.

\section{Isoflurane treatment}

The isoflurane treatment was similar to those in our previous studies $[65,70,71]$. We chose $2 \%$ isoflurane (air component: $2 \%$ isoflurane, $5 \% \mathrm{CO}_{2}, 21 \% \mathrm{O}_{2}$ and balanced nitrogen) in the studies based on our previous studies $[65,70,71]$. The control condition included $5 \%$ $\mathrm{CO}_{2}$ plus $21 \% \mathrm{O}_{2}$ (air component: $5 \% \mathrm{CO}_{2}, 21 \% \mathrm{O}_{2}$ and balanced nitrogen), which did not affect caspase-3 activation or $A \beta$ levels (Data not shown). The delivery of gases was similar to that described in our previous studies $[65,70]$. Briefly, $21 \% \mathrm{O}_{2}, 5 \% \mathrm{CO}_{2}$, and $2 \%$ isoflurane were delivered from an anesthesia machine to a sealed plastic box (airtight chamber) in a 37 degree $C$ incubator containing six-well plates seeded with one million cells in a $1.5 \mathrm{ml}$ cell culture media. The Datex infrared gas analyzer (Puritan-Bennett, Tewksbury, MA) was 
used to continuously monitor the concentrations of $\mathrm{CO}_{2}, \mathrm{O}_{2}$, and isoflurane that were delivered.

\section{Lysis of cells and protein amount quantification}

The pellets of the cells were detergent-extracted on ice using an immunoprecipitation buffer $(10 \mathrm{mM}$ Tris- $\mathrm{HCl}$, pH 7.4, $150 \mathrm{mM} \mathrm{NaCl}, 2$ mM EDTA, 0.5\% Nonidet P40) plus protease inhibitors $(1 \mathrm{~g} / \mathrm{ml}$ aprotinin, $1 \mathrm{~g} / \mathrm{ml}$ leupeptin, $1 \mathrm{~g} / \mathrm{ml}$ pepstatin A). The lysates were collected and centrifuged at $12,000 \times \mathrm{g}$ for 10 minutes, and then were quantified for total protein levels using the bicinchoninic acid protein assay kit (Pierce, Iselin, NJ).

\section{Western blot analysis}

The cells were harvested at the end of the experiments and were subjected to Western blot analyses using the methods described by Xie et al. [70]. BACE antibody (1:1,000 dilution; Abcam, Cambridge, MA) was used to recognize BACE (65 kDa). Antibody A8717 (1:1,000 dilution; Sigma, St. Louis, MO) was used to recognize FL-APP $(110 \mathrm{kDa})$ and APP-CTFs (10 to $12 \mathrm{kDa})$. A caspase- 3 antibody (1:1,000 dilution; Cell Signaling Technology, Inc. Beverly, MA) was used to recognize the caspase-3 fragment (17-20 kDa), which results from cleavage at the asparate position 175, and FL-caspase-3 $(35-40 \mathrm{kDa})$. An antibody to the non-targeted protein $\beta$-Actin (42 kDa, 1:5,000, Sigma) was used to control for loading differences in total protein amounts. Each band in the Western blot represents an independent experiment. We have averaged the results from three to six independent experiments. The intensity of signals in each Western blot was analyzed using the National Institute of Health image program (National Institute of Health Image 1.62, Bethesda, MD). We quantified the Western blots using two steps. First, we used levels of $\beta$-Actin to normalize (e.g., determine the ratio of the amount of FL-caspase- 3 to the amount of $\beta$-Actin) the levels of FL-caspase-3, caspase-3 fragment, BACE, FLAPP, and APP-CTFs to control for any loading differences in total protein amounts. Second, we presented changes in the levels of BACE, FL-APP, APP-CTFs, and caspase- 3 in the treated cells as percentages of those in cells from the control condition.

\section{Quantification of $A \beta$ using Sandwich ELISA assay}

Secreted $A \beta$ in the conditioned culture media was measured with a Sandwich ELISA assay by using an $A \beta$ measurement kit (Invitrogen, Carlsbad, CA) as described by Xie et al. [75]. Specifically, 96-well plates were coated with mouse monoclonal antibodies (mAb) specific to $A \beta_{40}$ (2G3) or $A \beta_{42}$ (21F12). Following blocking with Block Ace, wells were incubated overnight at $4^{\circ} \mathrm{C}$ with test samples of conditioned cell culture media, and then an anti-A $\beta$ ( $\beta$-A-HR1) antibody conjugated to horseradish peroxidase was added. Plates were then developed with TMB reagent and well absorbance was measured at $450 \mathrm{~nm}$. A $\beta$ levels in test samples were determined by comparison with the signal from unconditioned media spiked with known quantities of $A \beta_{40}$ and $\mathrm{A} \beta_{42}$.

\section{Statistics}

Given the presence of background caspase- 3 activation, $\mathrm{A} \beta, \mathrm{BACE}, \mathrm{FL}-\mathrm{APP}$, and APP-CTFs in the cells cultured in serum free media, we did not use absolute values to describe their changes. Instead, these changes were presented as percentages of those from the control group. For example, one hundred percent of caspase-3 activation refers to the control level for the purpose of comparison to experimental conditions. Data were expressed as mean \pm S.D.. The number of samples varied from three to six, and the samples were normally distributed. We used a two-tailed t-test to compare the difference between the control siRNA and BACE or APP siRNA, and the control condition and isoflurane treatment. Pvalues less than $0.05{ }^{(*)}$ and 0.01 (** or \#\#) were considered statistically significant.

\section{Results and discussion}

RNAi-mediated silencing of BACE attenuates the isoflurane-induced caspase- 3 activation

We previously reported that the commonly used inhalation anesthetic isoflurane can induce caspase activation and apoptosis in vitro $[65,70,71]$ and in vivo [64]. However, the underlying mechanisms of these effects remain largely to be determined. Specifically, $A \beta$ has been shown to potentiate the isoflurane-induced caspase-3 activation in $\mathrm{H} 4$ naïve cells, but it is largely unknown whether reduction in the levels of $A \beta$ can decrease the isoflurane-induced caspase- 3 activation in the cultured cells. BACE is the enzyme for $A \beta$ generation and APP is the precursor of $A \beta$. Decreases in the levels of BACE and APP could lead to reduction in A $\beta$ levels [3]. We therefore set out to assess the effects of RNAi-mediated silencing of BACE and APP on the levels of $A \beta$ and the isoflurane-induced caspase-3 activation in H4-APP cells.

The H4-APP cells were treated with control or BACE siRNA for 48 hours before the treatment with $2 \%$ isoflurane for six hours. The cells were harvested at the end of the experiment and were subjected to Western blot analysis. BACE immunoblotting showed that the BACE siRNA treatment decreased BACE levels as compared to the control siRNA treatment (Figure 1A). The quantification of the Western blots illustrated that BACE siRNA treatment significantly decreased BACE levels as compared to control siRNA: 100\% versus 57\% (Figure 1B). These findings suggest that the treatment with BACE siRNA, which targets at reducing mRNA 
C

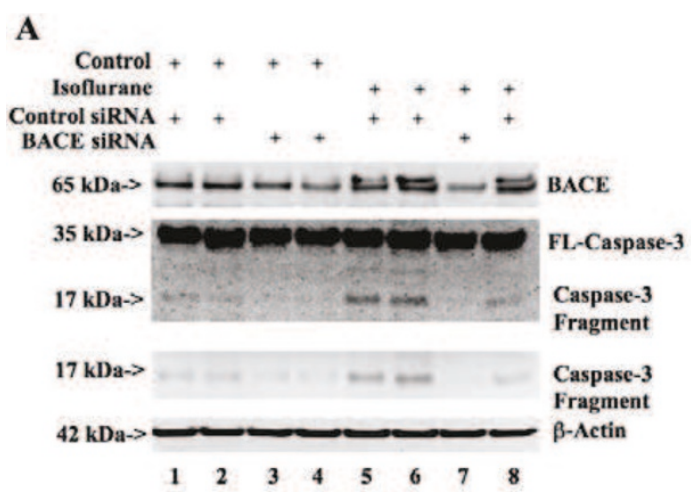

B

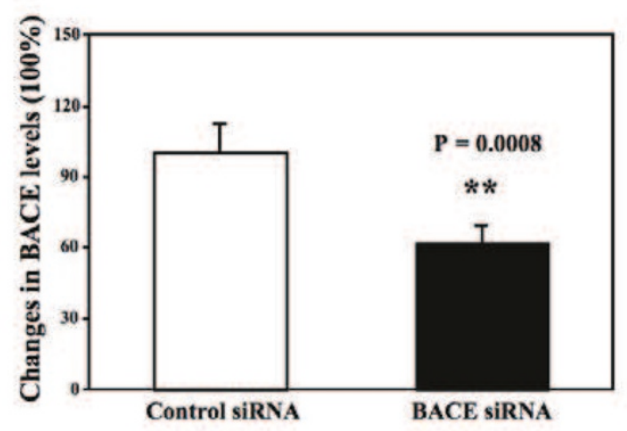

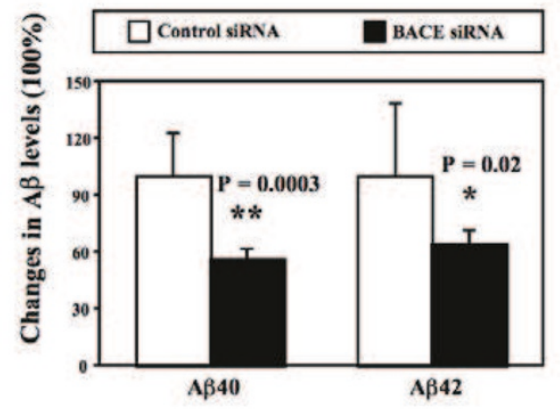

D

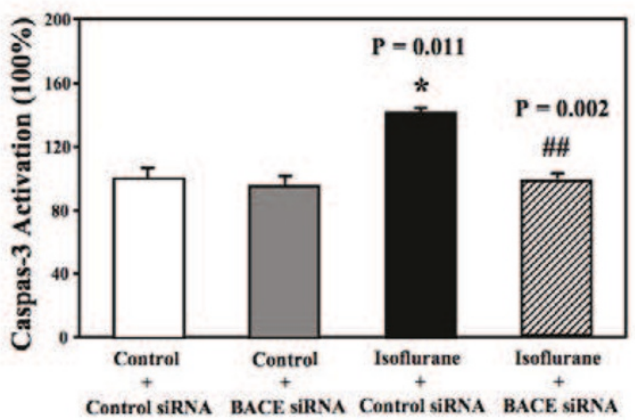

Figure 1 Effects of RNAi-mediated silencing of BACE on A $\boldsymbol{\beta}$ levels and caspase- 3 activation in H4-APP cells. A. Treatment of BACE siRNA (lanes 3, 4 and 7) decreases the levels of BACE as compared to control siRNA (lanes 1, 2, 5, 6 and 8) in the Western blotting analysis. Isoflurane treatment (lanes 5 and 6) induces caspase-3 activation as compared to control condition (lanes 1 and 2). The BACE siRNA treatment alone (lanes 3 and 4) does not induce caspase-3 activation. However, the BACE siRNA treatment (lane 7) attenuates the isoflurane-induced caspase-3 activation (lanes 5, 6 and 8) as compared to control siRNA treatment (lanes 5, 6 and 8). B. Quantification of the Western blots shows that BACE siRNA treatment (black bar) decreases the levels of BACE (** $P=0.0008)$ as compared to control siRNA treatment (white bar). C. BACE siRNA treatment (black bar) reduces the levels of $A \beta 40$ (left panel, ${ }^{* *} P=0.0003$ ) and $A \beta 42$ (right panel, ${ }^{*} P=0.02$ ) as compared to control siRNA treatment (white bar). D. Quantification of the Western blots shows that isoflurane (black bar, ${ }^{*} P=0.011$ ) induces caspase-3 activation as compared to control condition (white bar). BACE siRNA treatment (net bar, \#\# $\mathrm{P}=0.002$ ) attenuates the isoflurane-induced caspase-3 activation as compared to control siRNA plus isoflurane treatment (black bar).

levels of BACE, was able to reduce the protein levels of BACE in the current experiment. Next, we were able to show that the BACE siRNA treatment decreased the levels of both $A \beta 40$ (100\% versus $55 \%)$ and $A \beta 42(100 \%$ versus 63\%) (Figure 1C). These results suggested that the BACE siRNA was able to reduce $A \beta$ generation by decreasing the levels of $\mathrm{BACE}$, the enzyme of $\mathrm{A} \beta$ generation.

As expected, the caspase- 3 immunoblotting showed that the treatment with $2 \%$ isoflurane (lanes 5, 6 and 8) for six hours induced caspase- 3 activation, as evidenced by increased ratios of cleaved (activated) caspase-3 fragment (17 $\mathrm{kDa})$ to full-length (FL) caspase-3 (35 - $40 \mathrm{kDa}$ ), compared with control condition (lanes 1 and 2). Finally, we were able to show that the BACE siRNA treatment (lane 7) attenuated the isofluraneinduced caspase-3 activation (lanes 5, 6 and 8) (Figure 1A). The quantification of the Western blots showed that the isoflurane treatment (black bar) induced caspase- 3 activation as compared to control condition (white bar): $100 \%$ versus $148 \%$. The BACE siRNA treatment alone (gray bar) did not induce caspase activation. However, the BACE siRNA treatment attenuated the isoflurane-induced caspase- 3 activation (net bar) (Figure 1D): 148\% versus 103\%. These results illustrate that reduction in BACE levels, via RNAimediated silencing of $\mathrm{BACE}$, may lead to the reduction of $A \beta$ levels and the attenuation of the isofluraneinduced caspase- 3 activation.

RNAi-mediated silencing of APP attenuates the isofluraneinduced caspase-3 activation

Given the findings that reduction in the levels of both $B A C E$ and $A \beta$ is associated with the attenuation of the isoflurane-induced caspase- 3 activation, next, we would like to know whether other methods to reduce $A \beta$ levels 
can also lead to the attenuation of the isofluraneinduced caspase- 3 activation. Therefore, we set out to determine the effects of RNAi-mediated silencing of APP, the precursor of $A \beta$, on the levels of APP and $A \beta$, and on the isoflurane-induced caspase- 3 activation.

The H4-APP cells were treated with control or APP siRNA for 48 hours before the treatment with $2 \%$ isoflurane for six hours. The cells were harvested at the end of the experiment and were subjected to Western blot analysis. The APP immunoblotting showed that the APP siRNA treatment (lanes 3 and 4 ) decreased the levels of FL-APP and APP-CTFs as compared to the control siRNA treatment (lanes 1 and 2) (Figure 2A). The quantification of the Western blots showed that the APP siRNA treatment (black bar) decreased the levels of FL-APP (left panel, 100\% versus 26\%) and APP-CTFs (right panel, 100\% versus 23\%) as compared to control siRNA treatment (white bar). These results suggest that the RNAi-mediated silencing of APP was able to reduce the levels of APP in the H4-APP cells in the current experiment.

Next, we were able to show that the APP siRNA treatment reduced the levels of both $A \beta 40$ (left panel, 100\% versus $58 \%$ ) and $A \beta 42$ (right panel, $100 \%$ versus $66 \%$ ). Finally, the caspase- 3 immunoblotting showed that the APP siRNA treatment (lanes 3 and 4) decreased the isoflurane-induced caspase- 3 activation as compared to the control siRNA treatment (lanes 1 and 2) (Figure 2D). The quantification of the Western blots showed that the APP siRNA treatment (black bar) decreased the isoflurane-induced caspase- 3 activation as compared to control siRNA treatment (white bar): $100 \%$ versus $64 \%$. These results illustrated that the reduction in the levels of $A \beta$ and APP, resulting from RNAi-mediated silencing of APP, may also lead to the attenuation of isofluraneinduced caspase- 3 activation.

Taken together, these findings suggest that there is an association between the $A \beta$ levels and the isofluraneinduced caspase- 3 activation, specifically, the reduction of $A \beta$ levels, resulted from RNAi-mediated silencing of either BACE or APP, can lead to the attenuation of the isoflurane-induced caspase-3 activation.

Our previous studies have shown that the commonly used inhalation anesthetic isoflurane can induce caspase- 3 activation and apoptosis $[64,65,70,71]$. However, the underlying mechanism remains unclear and is an important question in the field of anesthesia neurotoxicity research. The previous studies in $\mathrm{H} 4$ naïve and H4APP cells have shown that the isoflurane-induced caspase-3 activation and apoptosis can enhance levels of BACE and $\gamma$-secretase, which promote APP processing and increase $A \beta$ generation [70]. Moreover, $A \beta$ can potentiate the isoflurane-induced caspase- 3 activation, leading to further rounds of apoptosis [70]. However, it is largely unknown whether reduction in $A \beta$ levels can attenuate the isoflurane-induced caspase- 3 activation. Therefore, we set out to assess the effects of RNAimediated silencing of APP, the precursor of $A \beta$, and $B A C E$, the enzyme of $A \beta$ generation, on $A \beta$ levels and on the isoflurane-induced caspase-3 activation in H4APP cells.

First, we have found that RNAi-mediated silencing of BACE can decrease BACE levels. These results suggest that the BACE siRNA-induced reduction in BACE mRNA levels can successfully decrease the protein levels of BACE in the current experiment. Then, we have found that there is a decrease in $A \beta$ levels following the BACE siRNA treatment. Finally, the BACE siRNA treatment attenuates the isoflurane-induced caspase- 3 activation in the H4-APP cells. These results have suggested that decreased $A \beta$ levels by the RNAi-mediated silencing of BACE may lead to the attenuation of the isofluraneinduced caspase- 3 activation. These results further support our previous findings that isoflurane may induce a vicious cycle of caspase- 3 activation/apoptosis and $A \beta$ accumulation [70].

The double bands for BACE in Figure 1A could be the isoforms of BACE. It is also possible that isoflurane induces a post-translational modification of BACE (e.g., phosphorylation). However, the RNAi of BACE decreases both bands of BACE, thus these findings still support the conclusion of current study that RNAimediated silencing of BACE can lead to a reduction in $A \beta$ levels and an attenuation of the isoflurane-induced caspase- 3 activation. As the key enzyme that initiates the formation of $\mathrm{A} \beta, \mathrm{BACE}$ is a prerequisite for the generation of $A \beta$, which gives rise to cerebrovascular and parenchymal amyloid plaque in the brain of $A D$ patients. Thus, it is important to identify these double bands following the isoflurane treatment in the future studies.

Previous in vivo studies have shown that a $50 \%$ reduction in BACE1 levels causes only a $12 \%$ decrease in $A \beta$ levels in heterozygous BACE1 gene knock-out mice [77]. However, our current in vitro studies have illustrated that a $43 \%$ reduction in BACE levels, following the BACE siRNA treatment, led to a $45 \%$ and a $37 \%$ reduction in the levels of $A \beta 40$ and $A \beta 42$, respectively. It is largely unknown why there is a difference between the in vitro and in vivo findings in the $A \beta$ levels. The possible explanations include the difference in the methods and experimental variability.

Decreased levels of BACE in heterozygous (BACE1 +/-) mice can lead to improvement of hippocampusindependent and -dependent form of memory deficits in the AD animal model [78,79]. Isoflurane has been shown to induce learning and memory impairment $[62,80,81]$. Our future studies, therefore, will include 
A

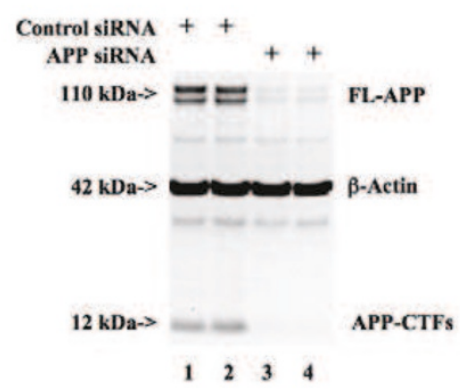

B

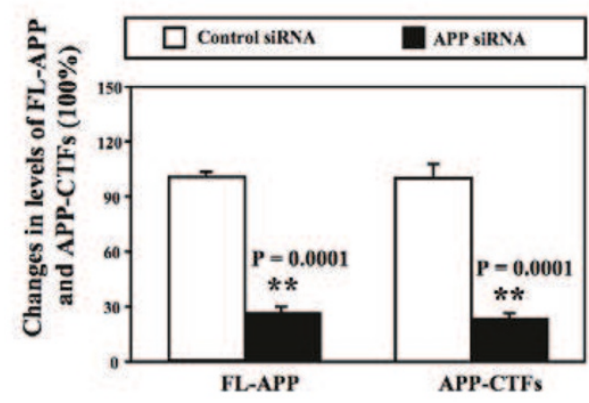

C

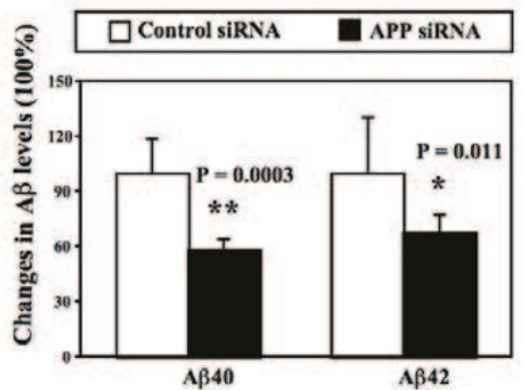

D

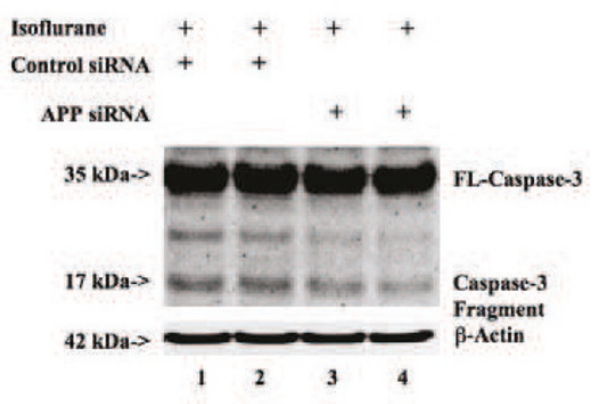

E

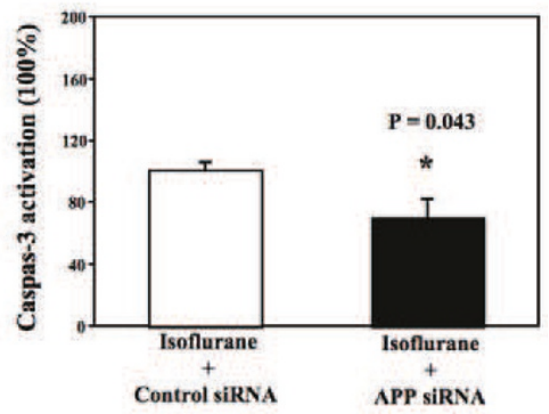

Figure 2 Effects of RNAi-mediated silencing of APP on A $\beta$ levels and caspase-3 activation in H4-APP cells. A. Treatment of APP siRNA (lanes 3 and 4) decreases the levels of FL-APP and APP-CTFs as compared to control siRNA (lanes 1 and 2) in the Western blotting analysis. B. Quantification of the Western blots shows that APP siRNA treatment (black bar) decreases the levels of FL-APP (left panel, ${ }^{* *}$ P $=0.0001$ ) and APP-CTFs (right panel, ${ }^{* *} P=0.0001$ ) as compared to control siRNA treatment (white bar). C. APP siRNA treatment (black bar) reduces the levels of $A \beta 40$ (left panel, ${ }^{* *} P=0.0003$ ) and $A \beta 42$ (right panel, ${ }^{*} P=0.011$ ) as compared to control siRNA treatment (white bar). D. APP siRNA treatment (lanes 3 and 4 ) attenuates the caspase-3 activation induced by isoflurane as compared to the control siRNA treatment (lanes 1 and 2) in the Western blotting analysis. E. Quantification of the Western blots shows that APP siRNA treatment (black bar, ${ }^{*} \mathrm{P}=0.043$ ) reduces the isoflurane-induced caspase-3 activation as compared to control siRNA plus isoflurane treatment (white bar).

assessing the effects of isoflurane on learning and memory in heterozygous (BACE1+/-) mice to further determine the role of $B A C E$ and $A \beta$ in the anesthesia associated neurotoxicity.
Next, we have further demonstrated the potential association of $A \beta$ accumulation and isoflurane-induced caspase- 3 activation by showing that RNAi-mediated silencing of APP can decrease the levels of FL-APP, 
APP-CTFs, A $\beta$, and finally the isoflurane-induced caspase- 3 activation. These findings have suggested that the reduction in $A \beta$ levels by decreasing the levels of its precursor i.e., APP, can also lead to the attenuation in the isoflurane-induced caspase- 3 activation.

Isoflurane has been reported to induce caspase activation and apoptosis $[64,65,70,76,82]$, [reviewed in [36,37]]. However, different findings do exist [83-93]. The reason for the different effects of isoflurane is largely unknown. Some studies have suggested that isoflurane may have a concentration and/or time-dependent dual effect (protective versus toxic) [94-96]. However, given the findings that increases and decreases in $A \beta$ levels can either potentiate [70] or attenuate (current findings) the isoflurane-induced caspase- 3 activation, respectively, it is possible that isoflurane may have different effects on caspase- 3 activation and apoptosis when different $A \beta$ levels are presented. Additional studies will be needed to further test this hypothesis by determining the effects of different concentrations of exogenously administrated $A \beta$ on the isoflurane-induced caspase-3 activation and apoptosis in vitro and in vivo.

\section{Conclusion}

In conclusion, we have found that RNAi-mediated silencing of either BACE or APP can lead to a reduction in $A \beta$ levels as well as an attenuation in the isofluraneinduced caspase- 3 activation. These results have further supported our previous findings that isoflurane induces caspase activation and apoptosis, which lead to $A \beta$ accumulation. $A \beta$ will then cause further rounds of caspase activation and apoptosis [70]. We would like to emphasize that although our current findings and the results from other studies have suggested that isoflurane may promote $\mathrm{AD}$ neuropathogenesis, it is still premature to conclude that isoflurane is toxic to use in patients. The in vivo relevance of these effects of isoflurane in humans remains largely to be determined. Nevertheless, our current findings should lead to additional studies to determine the potential effects of anesthetics on $\mathrm{AD}$ neuropathogenesis and the underlying mechanisms. These efforts will ultimately help facilitating the design of safer anesthetics and improved anesthesia care for patients, especially elderly individuals and patients with $\mathrm{AD}$.

\section{List of Abbreviation}

AD: Alzheimer's disease; APP: amyloid $\beta$ precursor protein; BACE: $\beta$-site amyloid precursor protein-cleaving enzyme; $A \beta$ : $\beta$-amyloid protein; CTFs: cterminal fragments.

\section{Acknowledgements}

This research was supported by K08NS048140, R21AG029856 and R01 GM088801 (National Institutes of Health), USA; Jahnigen Career

Development Award (American Geriatrics Society), USA; Investigator Initiated
Research Grant (Alzheimer's Association) USA (to Z. X.); National Science Foundation Oversea young scholar collaboration research award NSF30928036, P.R. China (to Y.Y. and Z. X.). The cost of anesthetic isoflurane was generously provided by the Department of Anesthesia, Critical Care and Pain Medicine, Massachusetts General and Hospital and Harvard Medical School, Boston, MA, USA.

\section{Author details}

${ }^{1}$ Geriatric Anesthesia Research Unit, Department of Anesthesia, Critical Care and Pain Medicine, Massachusetts General Hospital and Harvard Medical School, Charlestown, MA 02129-2060; USA. ²Department of Anesthesia, Beijing Chaoyang Hospital, Capital Medical University, Beijing, 100020, P.R. China. ${ }^{3}$ Department of Anesthesiology, Shanghai Eye, Ear, Nose and Throat Hospital, Fudan University, Shanghai 200031, P.R. China.

\section{Authors' contributions}

YD: Acquisition of data. ZX: Acquisition of data, Analysis and interpretation of data, Critical revision of the manuscript for important intellectual content. YZ: Acquisition of data, Critical revision of the manuscript for important intellectual content. SM: Critical revision of the manuscript for important intellectual content. HW: Administrative, technical, and material support. X S: Administrative, technical, and material support. YY: Obtained funding, Critical revision of the manuscript for important intellectual content. ZX: Obtained funding, Study concept and design, Analysis and interpretation of data, Drafting of the manuscript, Critical revision of the manuscript for important intellectual content, Study supervision. All authors read and have approved the manuscript.

\section{Authors' information}

Geriatric Anesthesia Research Unit, Department of Anesthesia, Critical Care and Pain Medicine, Massachusetts General Hospital and Harvard Medical School (Dong, Z., Xu, Z., Zhang, Y., McAuliffe, S., Wang, H., Shen, X., and Xie, Z.).

Department of Anesthesia, Beijing Chaoyang Hospital, Capital Medical University, Beijing, P.R. China (Wang, H. and Yue, Y.).

Department of Anesthesiology, Shanghai Eye, Ear, Nose and Throat Hospital, Fudan University, Shanghai 200031, P.R. China (Shen, X.).

\section{Competing interests}

The authors declare that they have no competing interests.

Received: 1 March 2011 Accepted: 28 April 2011

Published: 28 April 2011

\section{References}

1. Tanzi RE, Bertram L: Alzheimer's disease: The latest suspect. Nature 2008, 454:706-8.

2. Selkoe DJ: Alzheimer's disease: genes, proteins, and therapy. Physiol Rev 2001, 81:741-66

3. Xie Z, Tanzi RE: Alzheimer's disease and post-operative cognitive dysfunction. Exp Gerontol 2006, 41:346-59.

4. Holtzman DM, Deshmukh M: Caspases: a treatment target for neurodegenerative disease? Nat Med 1997, 3:954-5.

5. Lunkes A, Trottier Y, Mandel J: Pathological mechanisms in Huntington's disease and other polyglutamine expansion diseases. Essays Biochem 1998, 33:149-63.

6. Namura S, Zhu J, Fink K, et al: Activation and cleavage of caspase-3 in apoptosis induced by experimental cerebral ischemia. J Neurosci 1998, 18:3659-68.

7. Kim TW, Pettingell WH, Jung YK, Kovacs DM, Tanzi RE: Alternative cleavage of Alzheimer-associated presenilins during apoptosis by a caspase-3 family protease. Science 1997, 277:373-6.

8. Loetscher $H$, Deuschle U, Brockhaus M, et al: Presenilins are processed by caspase-type proteases. J Biol Chem 1997, 272:20655-9.

9. Barnes NY, Li L, Yoshikawa K, Schwartz LM, Oppenheim RW, Milligan CE: Increased production of amyloid precursor protein provides a substrate for caspase-3 in dying motoneurons. J Neurosci 1998, 18:5869-80.

10. Kovacs DM, Mancini R, Henderson J, et al: Staurosporine-induced activation of caspase- 3 is potentiated by presenilin 1 familial Alzheimer's disease mutations in human neuroglioma cells. J Neurochem 1999, 73:2278-85. 
11. Su JH, Anderson AJ, Cummings BJ, Cotman CW: Immunohistochemical evidence for apoptosis in Alzheimer's disease. Neuroreport 1994, 5:2529-33.

12. Su JH, Deng G, Cotman CW: Bax protein expression is increased in Alzheimer's brain: correlations with DNA damage, Bcl-2 expression, and brain pathology. J Neuropathol Exp Neurol 1997, 56:86-93.

13. Tesco G, Koh YH, Kang EL, et al: Depletion of GGA3 stabilizes BACE and enhances beta-secretase activity. Neuron 2007, 54:721-37.

14. Mattson MP: Contributions of mitochondrial alterations, resulting from bad genes and a hostile environment, to the pathogenesis of Alzheimer's disease. Int Rev Neurobiol 2002, 53:387-409.

15. Raina AK, Hochman A, Ickes $H$, et al: Apoptotic promoters and inhibitors in Alzheimer's disease: Who wins out? Prog Neuropsychopharmacol Biol Psychiatry 2003, 27:251-4.

16. LeBlanc AC: The role of apoptotic pathways in Alzheimer's disease neurodegeneration and cell death. Curr Alzheimer Res 2005, 2:389-402.

17. Cribbs DH, Poon WW, Rissman RA, Blurton-Jones M: Caspase-mediated degeneration in Alzheimer's disease. Am J Pathol 2004, 165:353-5.

18. Rohn T, Rissman RA, Head E, Cotman CW: Caspase Activation in the Alzheimer's Disease Brain: Tortuous and Torturous. Drug News Perspect 2002, 15:549-57.

19. Rohn TT, Rissman RA, Davis MC, Kim YE, Cotman CW, Head E: Caspase-9 activation and caspase cleavage of tau in the Alzheimer's disease brain. Neurobiol Dis 2002, 11:341-54.

20. Rohn T, Head E, Su JH, et al: Correlation between caspase activation and neurofibrillary tangle formation in Alzheimer's disease. Am J Pathol 2001, 158:189-98.

21. Rohn TT, Head E, Nesse WH, Cotman CW, Cribbs DH: Activation of caspase-8 in the Alzheimer's disease brain. Neurobiol Dis 2001, 8:1006-16.

22. Pompl PN, Yemul S, Xiang Z, et al: Caspase gene expression in the brain as a function of the clinical progression of Alzheimer disease. Arch Neurol 2003, 60:369-76

23. Yang F, Sun X, Beech W, et al: Antibody to caspase-cleaved actin detects apoptosis in differentiated neuroblastoma and plaque-associated neurons and microglia in Alzheimer's disease. Am J Pathol 1998, 152:379-89.

24. Gervais FG, Xu D, Robertson GS, et al: Involvement of caspases in proteolytic cleavage of Alzheimer's amyloid-beta precursor protein and amyloidogenic A beta peptide formation. Cell 1999, 97:395-406.

25. LeBlanc A, Liu H, Goodyer C, Bergeron C, Hammond J: Caspase-6 role in apoptosis of human neurons, amyloidogenesis, and Alzheimer's disease. J Biol Chem 1999, 274:23426-36.

26. Lu DC, Rabizadeh S, Chandra S, et al: A second cytotoxic proteolytic peptide derived from amyloid beta-protein precursor. Nat Med 2000, 6:397-404.

27. Eckert A, Marques CA, Keil U, Schussel K, Muller WE: Increased apoptotic cell death in sporadic and genetic Alzheimer's disease. Ann N Y Acad Sci 2003, 1010:604-9.

28. Zhao M, Su J, Head E, Cotman CW: Accumulation of caspase cleaved amyloid precursor protein represents an early neurodegenerative event in aging and in Alzheimer's disease. Neurobiol Dis 2003, 14:391-403.

29. Gastard MC, Troncoso JC, Koliatsos VE: Caspase activation in the limbic cortex of subjects with early Alzheimer's disease. Ann Neurol 2003, 54:393-8.

30. Hitomi J, Katayama T, Eguchi Y, et al: Involvement of caspase-4 in endoplasmic reticulum stress-induced apoptosis and Abeta-induced cell death. J Cell Biol 2004, 165:347-56.

31. Takuma H, Tomiyama T, Kuida K, Mori H: Amyloid beta peptide-induced cerebral neuronal loss is mediated by caspase-3 in vivo. $J$ Neuropathol Exp Neurol 2004, 63:255-61.

32. Shimohama S, Tanino H, Fujimoto S: Changes in caspase expression in Alzheimer's disease: comparison with development and aging. Biochem Biophys Res Commun 1999, 256:381-4.

33. Masliah E, Mallory M, Alford M, Tanaka S, Hansen LA: Caspase dependent DNA fragmentation might be associated with excitotoxicity in Alzheimer disease. J Neuropathol Exp Neurol 1998, 57:1041-52.

34. Moonesinghe SR, Mythen MG, Grocott MP: Review article: high-risk surgery: epidemiology and outcomes. Anesth Analg 2011, 112:891-901.

35. Weiser TG, Regenbogen SE, Thompson KD, et al: An estimation of the global volume of surgery: a modelling strategy based on available data. Lancet 2008, 372:139-44.
36. Tang J, Eckenhoff MF, Eckenhoff RG: Anesthesia and the old brain. Anesth Analg 2010, 110:421-6.

37. Bittner EA, Yue Y, Xie Z: Brief review: Anesthetic neurotoxicity in the elderly, cognitive dysfunction and Alzheimer's disease. Can J Anaesth 2011, 58(2):216-23.

38. Bohnen N, Warner MA, Kokmen E, Kurland LT: Early and midlife exposure to anesthesia and age of onset of Alzheimer's disease. Int J Neurosci 1994, 77:181-5

39. Bohnen NI, Warner MA, Kokmen E, Beard CM, Kurland LT: Alzheimer's disease and cumulative exposure to anesthesia: a case-control study. $J$ Am Geriatr Soc 1994, 42:198-201.

40. Lee TA, Wolozin B, Weiss KB, Bednar MM: Assessment of the emergence of Alzheimer's disease following coronary artery bypass graft surgery or percutaneous transluminal coronary angioplasty. J Alzheimers Dis 2005, 7:319-24.

41. Bufill E, Bartes A, Moral A, et al: [Genetic and environmental factors that may influence in the senile form of Alzheimer's disease: nested case control studies]. Neurologia 2009, 24:108-12

42. Monk TG, Weldon BC, Garvan CW, et al: Predictors of cognitive dysfunction after major noncardiac surgery. Anesthesiology 2008, 108:18-30.

43. Price CC, Garvan CW, Monk TG: Type and severity of cognitive decline in older adults after noncardiac surgery. Anesthesiology 2008, 108:8-17.

44. Moller JT, Cluitmans P, Rasmussen LS, et al: Long-term postoperative cognitive dysfunction in the elderly ISPOCD1 study. ISPOCD investigators. International Study of Post-Operative Cognitive Dysfunction. Lancet 1998, 351:857-61.

45. Newman MF, Kirchner $J$, Phillips-Bute $B$, et al: Longitudinal assessment of neurocognitive function after coronary-artery bypass surgery. $N$ Engl J Med 2001, 344:395-402.

46. Koch S, Forteza A, Lavernia C, et al: Cerebral fat microembolism and cognitive decline after hip and knee replacement. Stroke 2007, 38:1079-81.

47. Rodriguez RA, Tellier A, Grabowski J, et al: Cognitive dysfunction after total knee arthroplasty: effects of intraoperative cerebral embolization and postoperative complications. J Arthroplasty 2005, 20:763-71.

48. Bitsch M, Foss $N$, Kristensen B, Kehlet $H$ : Pathogenesis of and management strategies for postoperative delirium after hip fracture: a review. Acta Orthop Scand 2004, 75:378-89.

49. Bekker AY, Weeks EJ: Cognitive function after anaesthesia in the elderly. Best Pract Res Clin Anaesthesiol 2003, 17:259-72.

50. Amador LF, Goodwin JS: Postoperative delirium in the older patient. J Am Coll Surg 2005, 200:767-73.

51. McDonagh DL, Mathew JP, White WD, et al: Cognitive function after major noncardiac surgery, apolipoprotein E4 genotype, and biomarkers of brain injury. Anesthesiology 2010, 112:852-9.

52. Steinmetz J, Christensen KB, Lund T, Lohse N, Rasmussen LS: Long-term consequences of postoperative cognitive dysfunction. Anesthesiology 2009, 110:548-55.

53. Sanders RD, Maze M: Neuroinflammation and postoperative cognitive dysfunction: can anaesthesia be therapeutic? Eur J Anaesthesio/ 2010, 27:3-5.

54. Phillips-Bute B, Mathew JP, Blumenthal JA, et al: Association of neurocognitive function and quality of life 1 year after coronary artery bypass graft (CABG) surgery. Psychosom Med 2006, 68:369-75.

55. Deiner $\mathrm{S}$, Silverstein $\mathrm{JH}$ : Postoperative delirium and cognitive dysfunction. Br J Anaesth 2009, 103(Suppl 1):i41-6.

56. Tsai TL, Sands LP, Leung JM: An Update on Postoperative Cognitive Dysfunction. Adv Anesth 2010, 28:269-84.

57. Knopman DS, Petersen RC, Cha RH, Edland SD, Rocca WA: Coronary artery bypass grafting is not a risk factor for dementia or Alzheimer disease. Neurology 2005, 65:986-90.

58. Gasparini M, Vanacore N, Schiaffini C, et al: A case-control study on Alzheimer's disease and exposure to anesthesia. Neurol Sci 2002, 23:11-4

59. Avidan MS, Searleman AC, Storandt M, et al: Long-term cognitive decline in older subjects was not attributable to noncardiac surgery or major illness. Anesthesiology 2009, 111:964-70.

60. Harris RA, Eger El: Alzheimer's disease and anesthesia: out of body, out of mind...or not? Ann Neurol 2008, 64:595-7.

61. Culley DJ, Baxter MG, Crosby CA, Yukhananov R, Crosby G: Impaired acquisition of spatial memory 2 weeks after isoflurane and isoflurane- 
nitrous oxide anesthesia in aged rats. Anesth Analg 2004, 99:1393-7, table of contents.

62. Bianchi SL, Tran T, Liu C, et al: Brain and behavior changes in 12-monthold Tg2576 and nontransgenic mice exposed to anesthetics. Neurobiol Aging 2008, 29:1002-10.

63. Eckenhoff RG, Johansson JS, Wei H, et al: Inhaled anesthetic enhancement of amyloid-beta oligomerization and cytotoxicity. Anesthesiology 2004, 101:703-9.

64. Xie Z, Culley DJ, Dong Y, et al: The common inhalation anesthetic isoflurane induces caspase activation and increases amyloid betaprotein level in vivo. Ann Neurol 2008, 64:618-27.

65. Xie Z, Dong Y, Maeda U, et al: The common inhalation anesthetic isoflurane induces apoptosis and increases amyloid beta protein levels. Anesthesiology 2006, 104:988-94.

66. Brambrink AM, Evers AS, Avidan MS, et al: Isoflurane-induced neuroapoptosis in the neonatal rhesus macaque brain. Anesthesiology 2010, 112:834-41.

67. Planel E, Bretteville $A$, Liu $L$, et al: Acceleration and persistence of neurofibrillary pathology in a mouse model of tauopathy following anesthesia. FASEB J 2009, 23:2595-604.

68. Zhang $Y$, Dong $Y, W u X$, et al: The mitochondrial pathway of anesthetic isoflurane-induced apoptosis. J Biol Chem 2010, 285:4025-37.

69. Wu X, Lu Y, Dong Y, Zhang G, Zhang Y, Xu Z, Culley D, Crosby G, Marcantonio ER, Tanzi RE, Xie Z: The inhalation anesthetic isoflurane increases levels of proinflammatory cytokine TNF-alpha, IL-6 and IL1beta. Neurobiol Aging 2011.

70. Xie Z, Dong $Y$, Maeda $U$, et al: The inhalation anesthetic isoflurane induces a vicious cycle of apoptosis and amyloid beta-protein accumulation. J Neurosci 2007, 27:1247-54.

71. Xie Z, Dong Y, Maeda U, et al: Isoflurane-induced apoptosis: a potential pathogenic link between delirium and dementia. J Gerontol A Biol Sci Med Sci 2006, 61:1300-6.

72. Xie Z, Dong Y, Maeda U, Xia W, Tanzi RE: RNA interference silencing of the adaptor molecules ShcC and Fe65 differentially affect amyloid precursor protein processing and Abeta generation. J Biol Chem 2007, 282:4318-25.

73. Xie Z, Romano DM, Kovacs DM, Tanzi RE: Effects of RNA interferencemediated silencing of gamma-secretase complex components on cell sensitivity to caspase-3 activation. J Biol Chem 2004, 279:34130-7.

74. Xie Z, Romano DM, Tanzi RE: Effects of RNAi-mediated silencing of PEN-2, APH-1a, and nicastrin on wild-type vs FAD mutant forms of presenilin 1. J Mol Neurosci 2005, 25:67-77.

75. Xie Z, Romano DM, Tanzi RE: RNA interference-mediated silencing of X11alpha and X11beta attenuates amyloid beta-protein levels via differential effects on beta-amyloid precursor protein processing. I Biol Chem 2005, 280:15413-21.

76. Zhang G, Dong $Y$, Zhang B, et al: Isoflurane-induced caspase-3 activation is dependent on cytosolic calcium and can be attenuated by memantine. J Neurosci 2008, 28:4551-60.

77. McConlogue L, Buttini M, Anderson JP, et al: Partial reduction of BACE1 has dramatic effects on Alzheimer plaque and synaptic pathology in APP Transgenic Mice. J Biol Chem 2007, 282:26326-34.

78. Devi L, Ohno M: Genetic reductions of beta-site amyloid precursor protein-cleaving enzyme 1 and amyloid-beta ameliorate impairment of conditioned taste aversion memory in 5XFAD Alzheimer's disease model mice. Eur J Neurosci 2010, 31:110-8.

79. Kimura R, Devi L, Ohno M: Partial reduction of BACE1 improves synaptic plasticity, recent and remote memories in Alzheimer's disease transgenic mice. J Neurochem 2010, 113:248-61.

80. Culley DJ, Baxter MG, Yukhananov R, Crosby G: Long-term impairment of acquisition of a spatial memory task following isoflurane-nitrous oxide anesthesia in rats. Anesthesiology 2004, 100:309-14.

81. Saab BJ, Maclean AJ, Kanisek M, et al: Short-term memory impairment after isoflurane in mice is prevented by the alpha5 gammaaminobutyric acid type $\mathrm{A}$ receptor inverse agonist $\mathrm{L}-655,708$. Anesthesiology 2010, 113:1061-71.

82. Wei $H$, Kang $B$, Wei $W$, et al: Isoflurane and sevoflurane affect cell survival and BCL-2/BAX ratio differently. Brain Res 2005, 1037:139-47.

83. $\mathrm{Xu} \mathrm{X,} \mathrm{Feng} \mathrm{J,} \mathrm{Zuo} \mathrm{Z:} \mathrm{Isoflurane} \mathrm{preconditioning} \mathrm{reduces} \mathrm{the} \mathrm{rat} \mathrm{NR8383}$ macrophage injury induced by lipopolysaccharide and interferon gamma. Anesthesiology 2008, 108:643-50.
84. Li L, Peng L, Zuo Z: Isoflurane preconditioning increases B-cell lymphoma-2 expression and reduces cytochrome $c$ release from the mitochondria in the ischemic penumbra of rat brain. Eur J Pharmacol 2008, 586(1-3):106-13.

85. Raphael J, Zuo Z, Abedat S, Beeri R, Gozal Y: Isoflurane preconditioning decreases myocardial infarction in rabbits via up-regulation of hypoxia inducible factor 1 that is mediated by mammalian target of rapamycin Anesthesiology 2008, 108:415-25.

86. Zaugg M, Jamali NZ, Lucchinetti E, Shafiq SA, Siddiqui MA: Norepinephrine-induced apoptosis is inhibited in adult rat ventricular myocytes exposed to volatile anesthetics. Anesthesiology 2000, 93:209-18

87. Tyther R, Fanning N, Halligan M, Wang J, Redmond HP, Shorten G: The effect of the anaesthetic agent isoflurane on the rate of neutrophil apoptosis in vitro. Ir J Med Sci 2001, 170:41-4.

88. Wise-Faberowski L, Raizada MK, Sumners C: Oxygen and glucose deprivation-induced neuronal apoptosis is attenuated by halothane and isoflurane. Anesth Analg 2001, 93:1281-7.

89. Wise-Faberowski L, Aono M, Pearlstein RD, Warner DS: Apoptosis is not enhanced in primary mixed neuronal/glial cultures protected by isoflurane against N-methyl-D-aspartate excitotoxicity. Anesth Analg 2004, 99:1708-14, table of contents.

90. de Klaver MJ, Manning L, Palmer LA, Rich GF: Isoflurane pretreatment inhibits cytokine-induced cell death in cultured rat smooth muscle cells and human endothelial cells. Anesthesiology 2002, 97:24-32.

91. Kawaguchi M, Drummond JC, Cole DJ, Kelly PJ, Spurlock MP, Patel PM: Effect of isoflurane on neuronal apoptosis in rats subjected to focal cerebral ischemia. Anesth Analg 2004, 98:798-805, table of contents.

92. Gray JJ, Bickler PE, Fahlman CS, Zhan X, Schuyler JA: Isoflurane neuroprotection in hypoxic hippocampal slice cultures involves increases in intracellular $\mathrm{Ca} 2+$ and mitogen-activated protein kinases. Anesthesiology 2005, 102:606-15.

93. Lin D, Feng C, Cao M, Zuo Z: Volatile Anesthetics May Not Induce Significant Toxicity to Human Neuron-Like Cells. Anesth Analg 2010

94. Pan C, Xu Z, Dong Y, Zhang Y, Zhang J, McAuliffe S, Yue Y, Li T, Xie Z: The potential dual effects of anesthetic isoflurane on hypoxia-induced caspase-3 activation and increases in BACE levels. Anesth Analg 2011.

95. Xu Z, Dong Y, Wu X, Zhang J, McAuliffe S, Pan C, Zhang Y, Ichinose F, Yue $Y, X i e Z$ : The potential dual effects of anesthetic isoflurane on $A \beta$ induced apoptosis. Curr Alzheimer Res 2011.

96. Wei $H$, Liang $G$, Yang H: Isoflurane preconditioning inhibited isofluraneinduced neurotoxicity. Neurosci Lett 2007, 425:59-62.

doi:10.1186/2045-9912-1-5

Cite this article as: Dong et al:: RNA interference-mediated silencing of BACE and APP attenuates the isoflurane-induced caspase activation. Medical Gas Research 2011 1:5.

\section{Submit your next manuscript to BioMed Central and take full advantage of:}

- Convenient online submission

- Thorough peer review

- No space constraints or color figure charges

- Immediate publication on acceptance

- Inclusion in PubMed, CAS, Scopus and Google Scholar

- Research which is freely available for redistribution 